Gönderilme Tarihi: 21 Ekim 2015

Kabul Tarihi: 9 Mart 2016

\title{
YAZILIM PROJESİ SEÇİM PROBLEMİNDE ÇOK AMAÇLI OPTİMIZZASYON UYGULAMASI
}

\section{Gökçe BAYSAL TÜRKÖLMEZ*}

\author{
öz
}

İşletmeler bütçeleri dahilinde uygulamak istedikleri projeleri seçerken çok sayıda amacı göz önünde bulundururlar. Projenin türü ve işletmenin yapısına göre değişmekle birlikte, projenin faydası, karlılık, maliyet, verimlilik, risk ve sınırlı kaynaklar düşünülerek gerçekleştirilmeye çalışılmaktadır. Bu kriterler birbirleriyle ilişkili olduğundan, birlikte değerlendirilmeleri doğru bir seçimin yapılabilmesi için önemlidir. Bu çalışmada, bir yazılım firmasının yürüttüğü projeler içinden, belirlenen kriterler göz önüne alınarak en iyi projenin seçilmesi amaçlanmıştır. Çok Kriterli Karar Verme yöntemlerinden olan TOPSIS ve VIKOR ile projeler amaçları karşılama derecesine göre sıralanmıştır. Kriterler amaç fonksiyonları olarak düzenlenerek çok amaçlı evrimsel optimizasyon algoritması ile proje seçim problemi yeniden çözülmüştür. Tüm sonuçlar karşılaştırılarak en iyi projenin seçimi ile sonuca ulaşılmıştır.

Anahtar kelimeler: Proje Seçim Problemi, TOPSIS, VIKOR, ÇOK Amaçlı Optimizasyon

\section{AN APPLICATION OF MULTIOBJECTIVE OPTIMIZATION ON SOFTWARE PROJECT SELECTION PROBLEM}

\begin{abstract}
Companies consider a large number of objectives while selecting the projects according to their budgets. Although it varies depending on the type of the project and structure of the company, benefits of the project, profitability, cost, efficiency and risk profile of the project are taken into account within limited resources. Because these objectives are interrelated, they should be evaluated together for a right selection of the solving method. In this study, it is aimed to select the best project of a software company. Firstly, TOPSIS and VIKOR methods are used to order projects from the best to the worst. Then, the selection problem is resolved by multiobjective genetic algorithm. All results are compared and the best project is selected.
\end{abstract}

Keywords: Project Selection Problem, TOPSIS, VIKOR, Multiobjective Optimization

* Dokuz Eylül Üniversitesi, İktisadi ve İdari Bilimler Fakültesi, Ekonometri Bölümü, Buca, İzmir, E-posta:gokce.baysal@deu.edu.tr 


\section{Gökçe Baysal Türkölmez}

\section{GİRIS}

İşletmeler üretim süreçlerinde birden fazla projeyi aynı zamanda uygulamak durumunda kalabilirler. Özellikle yazılım firmaları gibi proje bazı işletmelerde sınırlı bir bütçe ile kısıtlı bir zamanda tüm projeleri uygulayabilmek zorlayıcı ve bazen de imkansız bir süreçtir. Bu nedenle işletmeler projelerin fayda, karlıık, maliyet, verimlilik ve risk durumlarını bilmek ve bu kriterlere göre sıralamasını görmek isterler. Böyle bir sıralama oluşturulabilirse, işletmelere bütçe, zaman ve işgücü kaynaklarını doğru projelere yönlendirmeleri ve yatıımlarını etkin yönetebilmeleri için önemli bilgi sağlanmış olur.

Bu çalışmada bir yazılım firmasının yönettiği projelerin belirlenen kriterlere göre değerlendirilmesi ve en karlı projenin belirlenmesi amaçlanmıştır. Yazılım firmasının yönettiği 6 proje için firma tarafından kriterler belirlenmiştir: kar, maliyet, verimlilik, risk ve sinerji. Bunlar arasından maliyet, verimlilik ve risk hesaplaması COCOMO II (Constructive Cost Model) programı kullanılarak yapılmıştır. COCOMO II, yaziım projelerini planlamak ve uygulamak için kullanılan objektif bir maliyet modelidir. Yazılım maliyet hesaplaması, yazılım projesinin kapsadığı tüm işlerin tamamlanması için gerekli kaynakların maliyetinin bir tahminidir. Özellikle büyük yazılım projeleri genellikle çizelgeden sapmalar, maliyet aşımları, kalite problemleri ve tüm işlemlerin iptali gibi durumlarla karşı karşıya kalmaktadır (Sharma, 2011: 1). Kar ve sinerji verileri firma tarafından sağlanmışıır. Sonrasında çok kriterli karar verme yöntemlerinden TOPSIS ve VIKOR kullanılarak projeler sıralanmıştır. Çok sayıda alternatifin olduğu problemlerde uygulama kolaylığı sağlaması ve alternatifleri en iyiden en kötüye sıralaması nedeniyle bu iki yöntem seçilmiştir. Kar, maliyet, verimlilik, risk ve sinerji fonksiyonları oluşturularak çok amaçlı evrimsel optimizasyon algoritması ile çözülmüş ve en karlı proje belirlenmiştir. Daha sonra tüm analiz sonuçları karşılaştırılarak sonuçlar yorumlanmıştır.

Çalışmada öncelikle literatürdeki önceki çalışmalar ve kullanılan yöntemler açıklanacaktır. Çok kriterli karar verme yöntemlerinden TOPSIS ve VIKOR'un aşamaları anlatılacaktır. Ardından çok amaçıı optimizasyon ve evrimsel algoritmaların teorik yapısı incelenecektir. Uygulama bölümünde COCOMO II programından bahsedilecek ve projelerin değerlendirme ve çözüm aşamaları anlatılacaktır. Analiz sonuçlarının yorumlanması sonuçlar bölümünde ele alınacaktır. 


\section{Yazılım Projesi Seçim Probleminde \\ Çok Amaçlı Optimizasyon Uygulaması}

\section{ÖNCEKİ ÇALIŞMALAR}

Proje seçim problemlerinde çok amaçlı/kriterli modellerin kullanıldığı birçok çalışma literatürde mevcuttur. Ringuest ve Graves (1989), araştırma ve geliştirme projelerinde çok amaçlı model tanımlamışlar ve hedef programlama ile çözülen bir problemi çok amaçlı optimizasyon algoritmasıyla çözmüşlerdir. Medaglia, Graves ve Rinquest (2007) rakip araştırma ve geliştirme projelerinin bir kümesi içinde sınırlı kaynakların dağııımı problemini incelemişlerdir. Bunlar kısmen finanse edilen, çok (stokastik) amaçlı, amaçları açısından aralarında bağlantı olan ve doğrusal kaynak kısıtlarına sahip projelerdir. Proje seçim problemini stokastik çok amaçlı doğrusal-kısıtlı optimizasyon yapısında oluşturmuşlar ve evrimsel çözüm yöntemlerinden olan NSGA algoritması ile çözmüşlerdir.

Ghorbani ve Rabbani (2009) proje seçim problemleri için yeni bir meta-sezgisel yöntem önermiş ve sonuçları NSGA II ile karşılaştırmışlardır. Seçilen projelerin toplam beklenen faydasının maksimize edildiği ve her ardışık zaman periyodu arasında tahsis edilen kaynağın mutlak varyasyonunun toplamının minimize edildiği iki fonksiyon amaç fonksiyonları olarak incelenmiştir. Önerilen algoritma, baskınlanmayan (non-dominated) çözümleri oluşturan memetik algoritma temelli, bir metasezgisel algoritmadır. Rabbani, Bajestani ve Khoshkhou (2010), yatırım tekliflerinin bir kümesi içinden en uygun projenin seçilmesi problemini çok amaçı parçacık sürü optimizasyonu modeli ile oluşturmuş ve çok amaçlı genetik algoritmalar ile çözmüşlerdir.

Kremmel, Kubalík ve Biffl (2010) yazılım projelerinin seçim probleminde öncelikle COCOMO II programı ile maliyet hesaplaması yapmış, ardından elde edilen değerleri kullanarak amaç fonksiyonlarını oluşturmuş, çok amaçlı evrimsel algoritmalarla çözüme ulaşmışlardır. Amiri (2012) çalışmasında, proje seçim probleminde harmoni arama algoritması temelli çok amaçlı evrimsel algoritma kullanmıştır. Harmonik aramanın genellikle yerel optimum noktaya yaklaşması problemini Kaotik Yerel arama ile birleştirerek çözmüştür.

\section{ÇÖZÜM YÖNTEMLERI}

Proje seçim problemlerinin çok kriterli/amaçlı yapısı nedeniyle, tüm kriterleri birlikte değerlendirecek yöntemler çözüm için seçilmiştir. Yazılım firması kriterler arasında bir derecelendirme yapmadığı için kriterler eşit ağırlıklandırımıştır. Çok kriterli karar verme yöntemlerinden TOPSIS, 


\section{Gökçe Baysal Türkölmez}

VIKOR ve çok amaçlı optimizasyon yöntemlerinin teorik yapıları ve çözüm algoritmaları sırasıyla verilmiştir.

\section{TOPSIS Yöntemi}

TOPSIS (Technique for Order Preference by Similarity to an Ideal Solution), Hwang ve Yoon tarafından 1981 yılında geliştirilen çok kriterli karar verme yöntemidir. Karar probleminin kriterlerine göre bir sıralama listesi sunar. Çözüm algoritmasında, ideal ve negatif-ideal çözüm olmak üzere iki referans noktası tanımlar. Temel prensibe göre, seçilen alternatifin ideal çözüme en kısa mesafede, negatif-ideal çözüme en uzak mesafede olması gerekmektedir. Uzaklık, n-boyutlu Euclidean uzaklığıdır (Opricovic ve Tzeng, 2004: 448). TOPSIS vektör normalizasyonunu kullanır ve normalize edilen değer, belirli bir kriterin farklı değerlendirme biriminde olabilir. TOPSIS'te en yüksek sıradaki alternatif, sıralama indeksine göre en iyi sonuçtur. Ancak bu sonuç, daima ideal çözüme en yakın sonuç demek değildir (Tzeng, Lin ve Opricovic, 2005: 1379).

TOPSIS aşağıdaki adımlarla çözülür (Triantaphyllou ve Lin, 1996: 284-286):

1. Normalize karar matrisi hesaplanır. Normalize değerler $n_{i j}$ aşağıdaki formüle göre bulunur:

$$
n_{i j}=\frac{x_{i j}}{\sqrt{\sum_{i=1}^{m} x_{i j}^{2}}}, i=1, \ldots, m, \quad j=1, \ldots, n .
$$

2. Ağırlıklandıııımış normalize karar matrisi $v_{i j}$ hesaplanır:

$$
v_{i j}=w_{j} n_{i j}, i=1, \ldots, m, j=1, \ldots, n \text {, }
$$

$w_{j}, i$ kriterin ağırlığıdır ve $\sum_{j=1}^{n} w_{j}=1$.

3. Pozitif ideal ve negatif ideal çözümler belirlenir.

$$
\begin{aligned}
& A^{+}=\left\{v_{1}^{+}, \ldots, v_{n}^{+}\right\}=\left\{\left(\max _{j} v_{i j} \mid i \in I\right),\left(\min _{j} v_{i j} \mid i \in J\right)\right\}, \\
& A^{-}=\left\{v_{1}^{-}, \ldots, v_{n}^{-}\right\}=\left\{\left(\min _{j} v_{i j} \mid i \in I\right),\left(\max _{j} v_{i j} \mid i \in J\right)\right\},
\end{aligned}
$$

$I$ fayda kriterini ve $J$ maliyet kriterini gösterir.

4. $\quad n$ boyutlu Euclidean uzaklığı kullanılarak ayrım ölçüleri hesaplanır. Her alternatifin ideal çözümden ayrımı aşağıdaki gibi bulunur:

$$
d_{i}^{+}=\left\{\sum_{j=1}^{n}\left(v_{i j}-v_{j}^{+}\right)^{2}\right\}^{1 / 2}, i=1, \ldots, m,
$$

Benzer şekilde, negatif ideal çözümden ayrım aşağıdaki gibi hesaplanır:

$$
d_{i}^{+}=\left\{\sum_{j=1}^{n}\left(v_{i j}-v_{j}^{+}\right)^{2}\right\}^{1 / 2}, i=1, \ldots, m,
$$




\section{Yazılım Projesi Seçim Probleminde \\ Çok Amaçlı Optimizasyon Uygulaması}

5. İdeal çözüme göreli yakınlık hesaplanır. $A_{i}$ alternatifinin göreli yakınlığı; $A^{+}$ile gösterilir, aşağıdaki gibi hesaplanır:

$R_{i}=d_{i}^{-} /\left(d_{i}^{+}+d_{i}^{-}\right), i=1, \ldots, m . d_{i}^{-} \geq 0 \mathrm{ve} d_{i}^{+} \geq 0$ olduğundan, $R_{i} \in$ $[0,1]$.

6. Tercih sırası derecelendirilir. Bu indeksi kullanarak alternatifleri sıralamak için, alternatifler azalan sırada sıralanır.

\section{VIKOR Yöntemi}

VIKOR (Vise Kriterijumska Optimizacija I Kompromisno Resenje), karmaşık sistemlerin çok kriterli optimizasyonu için geliştirilmiştir. Yöntem, uzlaşık sıralama-listesi, uzlaşık çözüm ve verilen bireysel ağırlık değerleriyle elde edilen uzlaşık çözümün tercih stabilitesi için ağırık stabilite aralıklarını belirler. Çatışan kriterlerin mevcut olduğu durumda alternatifler kümesinden sıralama ve seçime odaklanmaktadır. (Opricovic ve Tzeng, 2004: 447). İdeal çözüm olarak bir referans noktası vardır. Çok kriterli sıralama indeksi ideal çözüme yakınlı̆ın belirli bir ölçüsünü temel alır ve avantaj oranlı bir uzlaşık çözüm önermektedir. Uzlaşık çözüm, ideal çözüme en yakın olurlu çözümdür ve uzlaşı, alternatifler arasında karşlıklı ödünlerle kurulan bir anlaşmadır (Chatterjee, Athawale ve Chakraborty, 2010: 484). Doğrusal normalizasyon kullanılır ve normalize değer kriterin değerlendirme birimine bağlı değildir. İdeal çözümden uzaklığı gösteren bir toplanma fonksiyonu tanımlar. Bu sıralama indeksi, tüm kriterlerin, kriterlerin göreli öneminin ve toplam ve bireysel memnuniyet arasındaki dengenin toplanmasıdır (Opricovic ve Tzeng, 2004: 447). VIKOR sonucunda en yüksek sıralı alternatif, ideal çözüme en yakın çözümdür. Uzlaşık sıralama için çok kriterli ölçüt, uzlaşık programlama yönteminde kullanılan Lp-ölçüsünden geliştirilmiştir (Zeleny, 1982: 169).

$$
L_{p j}=\left\{\sum_{i=1}^{n}\left[w_{i}\left(f_{i}^{*}-f_{i j}\right) /\left(f_{i}^{*}-f_{i}^{-}\right)\right]^{p}\right\}^{1 / p}, 1 \leq p \leq \infty ; j=1,2, \ldots, J .
$$

Uzlaşık sıralama algoritması VIKOR aşağıdaki adımlarla uygulanır (Opricovic ve Tzeng, 2004: 447):

1. Tüm kriter fonksiyonları için en iyi $f_{i}^{*}$ ve en kötü $f_{i}^{-}$değerleri belirlenir, $i=1,2, \ldots, n$.

2. $S_{j}$ ve $R_{j}, j=1,2, \ldots, J$ değerleri hesaplanır, aralarında aşağıdaki ilişki vardır:

$$
S_{j}=\sum_{i=1}^{n} w_{i}\left(f_{i}^{*}-f_{i j}\right) /\left(f_{i}^{*}-f_{i}^{-}\right) \quad R_{j}=\max _{i}\left[w_{i}\left(f_{i}^{*}-f_{i j}\right) /\right.
$$

$\left.\left(f_{i}^{*}-f_{i}^{-}\right)\right]$

$w_{i}, i=1,2, \ldots, n$ göreli önemlerine göre kriterlerin ağırlıklarıdır.

3. $Q_{j}, j=1,2, \ldots, J$ değerleri hesaplanır. 


\section{Gökçe Baysal Türkölmez}

$$
\begin{gathered}
Q_{j}=\frac{v\left(S_{j}-S^{*}\right)}{S^{-}-S^{*}}+\frac{(1-v)\left(R_{j}-R^{*}\right)}{R^{-}-R^{*}} \\
S^{*}=\min _{j} S_{j}, S^{-}=\max _{j} S_{j}, R^{*}=\min _{j} R_{j}, R^{-}=\max _{j} R_{j}, \text { ve } v \text { kriterlerin }
\end{gathered}
$$
çoğunluğunun strateji ağırlığı olarak tanımlanır.

4. $S, R$, ve $Q$ değerlerinin sınıflandırmalarına göre alternatifler azalan sıralama ile sıralanır.

5. Eğer aşağıdaki iki şart sağlanmışsa, $Q$ (minimum) ölçüsüyle en iyi olarak derecelenen ( $a^{\top}$ ) alternatifine bir uzlaşık çözüm önerilir:

C1: "Kabul edilebilir avantaj"

$D Q=1 /(J-1) ; \mathrm{J}$ alternatif sayısıdır

$a^{\prime \prime} ; Q$ sıralama listesinde ikinci durumdaki alternatiftir.

$$
Q\left(a^{\prime \prime}\right)-Q\left(a^{\prime}\right) \geq D Q
$$

C2: "Karar vermede kabul edilebilir kararlıık". Alternatif $a^{\prime}$ aynı zamanda S ve/veya R sıralamalarında da en iyi olarak derecelenmelidir. Bu uzlaşık çözüm, "çoğunluk kuralıyla oylama" ( $v>0.5$ olması gerekir) veya "consensus ile" $v \approx 0.5$, veya "veto ile" $(v<0.5)$ olarak tanımlanan karar verme süreci içinde durağandır. Burada, $v$ karar verme stratejisi "kriterlerin çoğunluğu"nun (veya "maksimum grup faydası") ağırlığıdır.

Eğer bu şartlardan biri sağlanmazsa, aşağıdaki şekilde oluşturulan bir uzlaşık çözümler kümesi önerilir:

Eğer yalnızca C2 şartı sağlanmamışsa, alternatifler $a^{\prime}$ ve $a$ " veya $C 1$ şartı sağlanmamışsa, alternatifler $a^{\prime}, a^{\prime \prime}, \ldots, a^{(M)} ;$ ve $a^{(M)}$, maksimum $M$ için $Q\left(a^{(M)}\right)-Q(a)<D Q$ ilişkisiyle belirlenir (bu alternatiflerin durumu "yakınlık"tır).

$Q$ ile sıralanan en iyi alternatif, $Q$ nun minimum değerli olanıdır. Asıl sıralama sonucu, alternatiflerin uzlaşık sıralama listesi ve "avantaj oranı" uzlaşık çözümdür.

\section{Çok Amaçlı Optimizasyon}

Çok amaçlı optimizasyon problemlerinde, birden fazla amaç fonksiyonu, varsa kısıtlar ve değişken sınırları da dikkate alınarak, birlikte çözülür. Bu çözümü gerçekleştirebilmek için kullanılan çok amaçlı optimizasyon yöntemleri iki kategori içinde incelenmektedir: Sayısallaştırma yaklaşımı ve Pareto yaklaşımı (De Weck, 2004: 5). İki farkı yaklaşım olsa da nihai amaç, tasarımcılar ya da karar vericiler için alternatifler içinden optimal bir kümenin oluşturulmasıdır.

Sayısallaştırma yaklaşımında, amaç fonksiyonları çeşitli dönüşümler kullanılarak tek amaç fonksiyonu içinde birleştirilir. Amaç fonksiyonlarının tek amaç fonksiyonunda birleştirilmesi, çözümde bir tek sonuç 
bulunmasına yol açar. Çok amaçlı yapıyı böyle tek sonuca indirgemek, bilgi kaybına neden olmaktadır. Arama uzayı konveks değilse, çözüme ulaşılamayabilir.
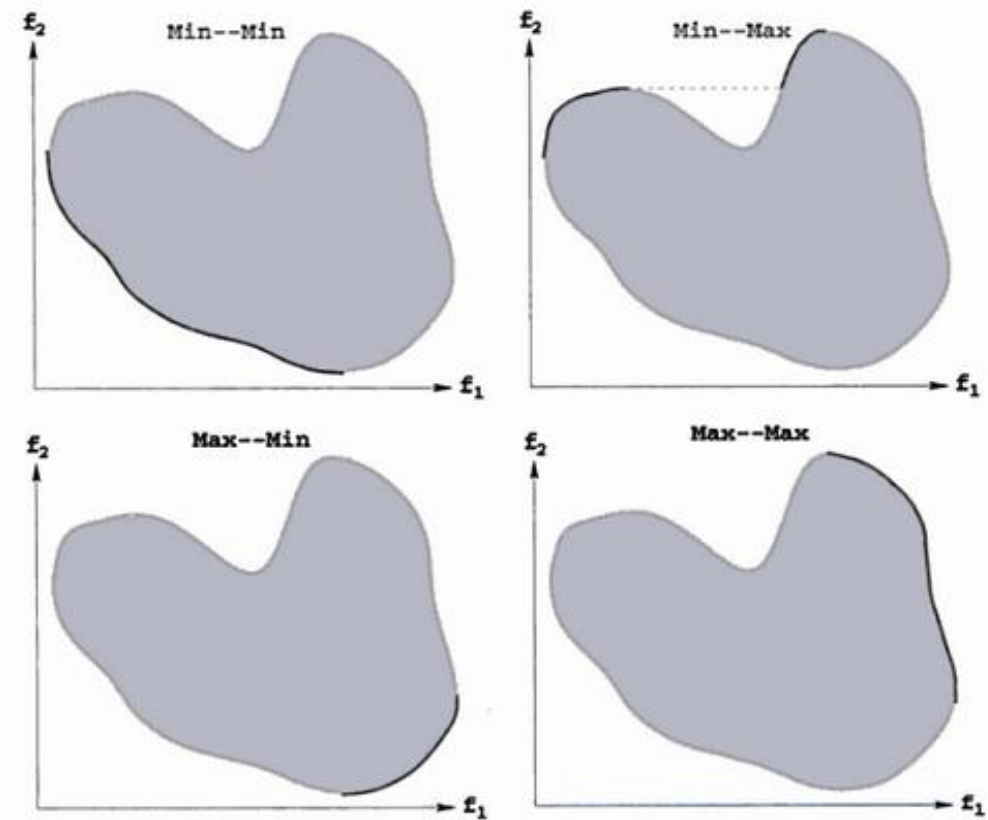

Kaynak: Deb, 2001: 32 (Pareto-optimal çözüm alanları, koyu renk sürekli eğriler ile gösterilmiştir)

\section{Şekil 1: İki Amaç Fonksiyonunun Dört Farklı Kombinasyonu İçin, Pareto-Optimal Çözüm Alanları}

Pareto yaklaşımında ise tek çözüm noktası bulmak yerine optimal çözümlerin bir kümesi elde edilir. Optimal çözümler, tüm çözüm kümesi içindeki üstün çözümlerdir ve Pareto sınır adı verilen bölgede oluşurlar.

Çok amaçlı optimizasyon problemi aşağıdaki gibi tanımlanır $\min \left\{f_{1}(x), \ldots, f_{p}(x)\right\}$

$x \in S$ olmak üzere,

formüldeki $p(\geq 2), f_{i}: \mathfrak{R}^{n} \rightarrow \mathfrak{R}$ amaç fonksiyonlarını gösterir. Amaç fonksiyonlarının vektörü $f(x)=\left(f_{1}(x), f_{2}(x), \ldots, f_{p}(x)\right)^{T}$ ile gösterilir. Karar (değişken) vektörleri $x=\left(x_{1}, x_{2}, \ldots, x_{n}\right)^{T}, \mathfrak{R}^{n}$ karar değişkeni uzayının bir alt kümesi olan, $\mathrm{S}$ uygun bölgesine (kümesine) aittir. Çok amaçlı optimizasyon probleminin amacı, tüm amaç fonksiyonlarını eş 


\section{Gökçe Baysal Türkölmez}

zamanlı olarak minimize etmektir. Çok amaçlı optimizasyon probleminin içerdiği amaç fonksiyonlarının birlikte çözümünden Pareto-optimal küme elde edilebilmesi için, öncelikle amaç fonksiyonları arasında bir ilişki olduğu varsayılmaktadır. Bu ilişki, amaç fonksiyonlarının ikili karşılaştırmasını içerir. Pareto-optimal küme, amaç fonksiyonlarının birlikte çözümünden elde edilen çözüm noktalarının üstünlük ilişkisi içinde karşılaştırılmasıyla oluşturulur. Üstün ya da baskın olma (domine etme) olarak tanımlanabilen bu karşılaştırma sonucu elde edilen en iyi ve birbirine üstün gelemeyen noktalar, Pareto-optimal kümeyi oluşturur. Amaç fonksiyonları arasında çatışma (ilişki) yoksa, çözüm her amaç fonksiyonunun kendi optimum noktasında bulunacaktır (Miettinen, 1999: 5).

Problemin maksimizasyon ya da minimizasyon yapısına göre Paretooptimal kümenin yeri farklılık gösterir (Şekil 1). Her problem yapısı için, Pareto-optimal küme daima uygun arama bölgesinin özel bir kenarındaki çözümlerden oluşur (Deb, 2001: 30-31).

Problemin çok amaçlı optimizasyon problemine dönüştürülmesi. Problemin çok amaçlı optimizasyon çözümü için beş amaç fonksiyonu oluşturulmuştur.

1. Potansiyel kar: $q_{1}(x)=\sum_{i=1}^{p} f_{i}(x)$

$f_{i}(x)=r_{i} \cdot w_{i}$; eğer $x_{i}>0$ ise $w_{i}=1, x_{i}=0$ ise $w_{i}=0$ değerini alır. Kar maksimizasyonu istenen durumdur.

2. Toplam maliyet: $q_{2}(x)=\sum_{i=1}^{p} c_{i}(x)$

Maliyet minimizasyonu amaçlanır.

3. Verimlilik: $q_{3}(x)=\sum_{i=1}^{p} v_{i}(x)$

Verimliliğin maksimizasyonu amaçlanır.

4. $\quad$ Risk: $q_{4}(x)=\sum_{i=1}^{p} d_{i}(x)$

$d_{i}(x)$, projelerin yüzde risk değerleri

Risk minimizasyonu amaçlanır.

5. Sinerji: $q_{5}(x)$

Bu kalite ölçüsü seçilen projeler arasındaki pozitif ve negatif etkiyi açıklar.

Pozitif sinerjide maksimizasyon, negatif sinerjide minimizasyon amaçlanır.

Pozitif sinerji değerleri: $y^{+}(x)=\sum_{i=1}^{p} y_{i}^{+}(x)$

Negatif sinerji değerleri: $y^{-}(x)=\sum_{i=1}^{p} y_{i}^{-}(x)$

$q_{5}(x)=y^{+}(x)-y^{-}(x)$ Amaç fonksiyonu maksimizasyon yönlüdür.

Çok amaçlı optimizasyonda evrimsel algoritmaların kullanımı. Gerçek hayat problemlerinin genellikle fazla sayıda amaç fonksiyonu içeren 


\section{Yazılım Projesi Seçim Probleminde \\ Çok Amaçlı Optimizasyon Uygulaması}

ve matematiksel olarak daha karmaşık olabilen yapısına uygun çözüm yöntemleri geliştirmek amacıyla farklı disiplinlerden yararlanılmışıı. Bu bağlamda, evrimsel algoritmaların çok amaçlı optimizasyon yöntemlerine uyarlanması, problemin gerçek çözümüne en iyi yakınsamayı veren Paretooptimal çözüm kümelerine ulaşılmasını sağlamıştır.

Evrimsel algoritmalar, biyolojik evrimin özelliklerinden yararlanılarak oluşturulmuş algoritmalardır. Mutasyon, çaprazlama, üreme gibi biyolojik çeşitlilik için önemli yapıların algoritma içine dahil edilmesiyle, çözüm noktalarında çeşitliliği ve problemin çözüm aralığı içinde yeni noktaların elde edilmesini sağlar. Klasik yöntemlerden farklı olarak, bir tek simülasyon çalışıımasında çoklu sonuçları bulması, Evrimsel Algoritmaların eşsiz bir özelliğidir (Deb, 2001: 77). Sadece bu özellik bile Evrimsel Algoritmalara, Çok Amaçıı Optimizasyon problemlerinin çözümünde kullanılması için çok büyük bir avantaj sağlar.

Son yirmi yıldan fazladır bilim, ticaret ve mühendislik alanlarındaki çeşitli problemlerde genetik algoritmalar, arama ve optimizasyon aracı olarak yoğun bir şekilde kullanıımaktadırlar. Başarısının ana nedenleri, çok çeşitli alanlara uygulanabilirliği, kullanım kolaylığı ve global perspektifidir (Goldberg, 1989: 22). Genetik Algoritmalar ve Evrim Stratejileri (ES) en çok bilinen Çok Amaçlı Evrimsel Algoritmalarda temel algoritmalar olarak kullanilır (Deb, 2001: 159).

\section{UYGULAMA}

Bir bilgisayar yazılım firması, firma içinde yürüteceği projeler içinden bir seçim yapmak istemektedir. Bu amaçla proje havuzundaki projeleri mevcut kriterlere göre sıralamayı, karlılık açısından değerlendirme yapmayı planlamaktadır. Proje seçimi için öncelikle Çok Amaçlı Karar Verme tekniklerinden TOPSIS ve VIKOR uygulanmış, sonuçlar Genetik Algoritmalı Çok Amaçlı Optimizasyon çözümüyle karşılaştırılmış, karılıı̆a göre bir değerlendirme yapılmıştır. Projelerin kar, maliyet, sinerji ve risk verileri yazııım firması tarafından verilmiştir. Kar ve maliyet Dolar cinsindendir. Risk değerleri yüzde olarak hesaplanmıştır. Sinerji için de firmanın belirlediği sinerji puanları kullanılmıştır. Projelerin verimlilikleri, COCOMO II programıyla hesaplanmışııı (Şekil 2)

Yazılım firması uluslararası bir firma olduğu için projelerin isimleri İngilizce, para birimi dolar cinsindendir. 


\section{Gökçe Baysal Türkölmez}

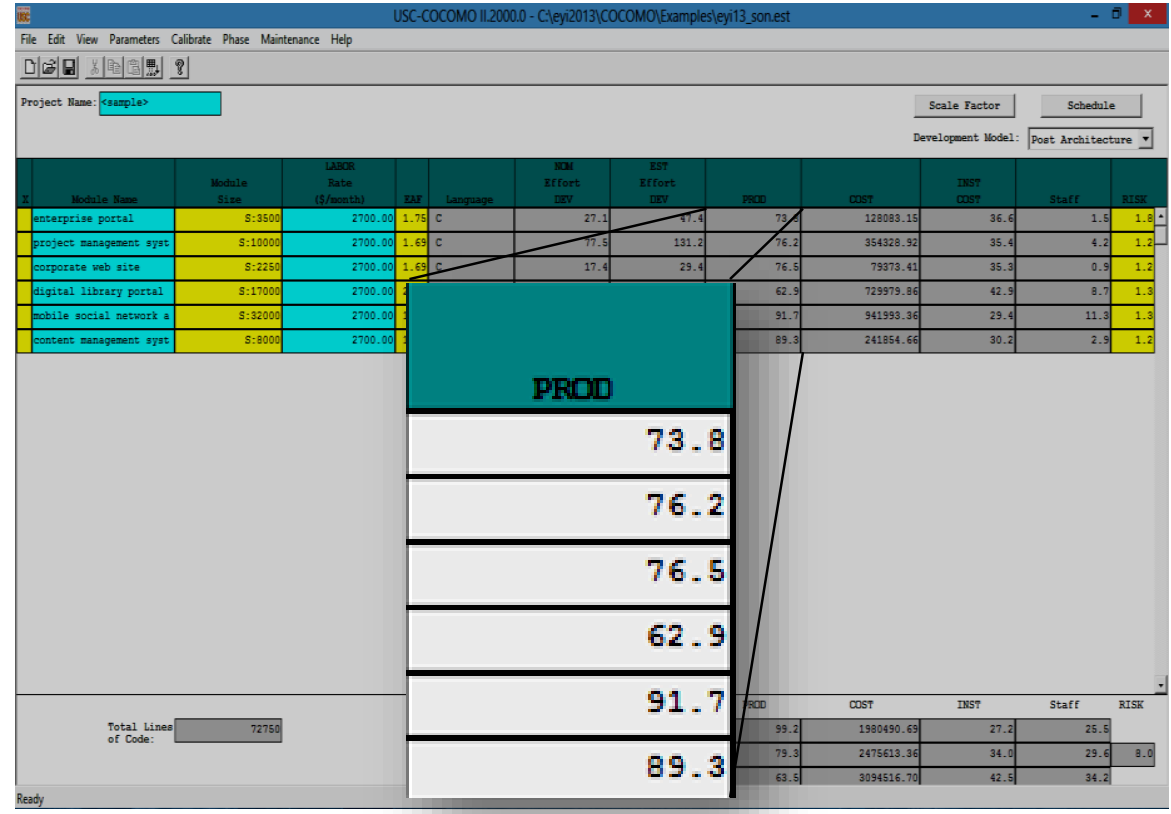

Şekil 2: COCOMO II Programıyla Hesaplanan Proje Değerlendirme Kriterleri

Yazılım firması tarafından oluşturulan değerlendirme kriterlerinden kar, verimlilik ve sinerjide maksimizasyon, maliyet ve riskte minimizasyon amaçlanmaktadır. Projelere ait tüm veriler Tablo 1'de gösterilmiştir.

\section{Tablo 1: Projelerin Verileri}

\begin{tabular}{|l|l|l|l|l|l|}
\hline Proje & Kar (Dolar) & $\begin{array}{l}\text { Maliyet } \\
\text { (Dolar) }\end{array}$ & $\begin{array}{l}\text { Verimlilik } \\
\text { (Yüzde) }\end{array}$ & Risk & $\begin{array}{l}\text { Sinerji } \\
\text { Puanı }\end{array}$ \\
\hline Enterprise Portal & 20.000 & $142.314,6$ & 73,8 & 0,775 & 0,5 \\
\hline $\begin{array}{l}\text { Project } \\
\text { Management } \\
\text { System }\end{array}$ & 100.000 & $393.698,8$ & 76,2 & 0,85 & 1 \\
\hline $\begin{array}{l}\text { Corporate Web } \\
\text { Site }\end{array}$ & 5.000 & $88.192,68$ & 76,5 & 0,85 & 0 \\
\hline Digital Library & 70.000 & $811.088,7$ & 62,9 & 0,8375 & 0,7 \\
\hline $\begin{array}{l}\text { Mobile Social } \\
\text { Network App }\end{array}$ & 100.000 & 1.046 .659 & 91,7 & 0,8375 & 0 \\
\hline $\begin{array}{l}\text { Content } \\
\text { Management } \\
\text { System }\end{array}$ & 0 & $268.727,4$ & 89,3 & 0,85 & 3,2 \\
\hline
\end{tabular}




\section{Yazılım Projesi Seçim Probleminde}

Çok Amaçlı Optimizasyon Uygulaması

Veriler incelendiğinde görülmektedir ki, en yüksek kar "Project Management System" ve "Mobile Social Network App" projelerinden elde ediliyorken, en yüksek verimliliğe sahip projeler "Mobile Social Network App" ve "Content Management System" projeleridir. "Content Management System" projesi en yüksek sinerji değerine sahip olmasına rağmen, kar getirmemektedir. En düşük maliyetli proje "Corporate Web Site", kar, verimlilik, sinerji açısından düşük değerlere ve yüksek riske sahiptir. Bu çok kriterli yapıda alternatifleri oluşturan projelerin hiçbiri tek başına en iyi olma özelliğine sahip değildir. Tüm kriterlerin birlikte değerlendirilerek alternatiflerin sıralanması gerekmektedir. Bu amaçla öncelikle proje seçim problemine TOPSIS ve VIKOR yöntemleri uygulanmıştır.

\section{Çok Kriterli Karar Verme Yöntemleri ile Çözüm}

Yazılım firması tarafından belirlenen beş kritere göre altı projenin TOPSIS ve VIKOR çözüm algoritmalarıyla değerlendirilmesi, yatıım yapılacak en uygun projenin seçilmesinde karar vericiye önemli bilgi ve destek sağlamaktadır. Çözüm sonucunda projelerin en iyiden en kötüye doğru sıralanması Tablo 2'de verilmiştir. TOPSIS için 1'e en yakın çözüm en iyi olarak seçilirken, VIKOR yönteminde ideal çözüme en az uzaklığa sahip alternatif en iyi çözümdür.

Tablo 2: TOPSIS ve VIKOR Çözümü

\begin{tabular}{|c|c|c|c|}
\hline \multicolumn{2}{|l|}{ TOPSIS } & \multicolumn{2}{|l|}{ VIKOR } \\
\hline & Ci* & & Qj \\
\hline $\begin{array}{l}\text { Project } \\
\text { Management } \\
\text { System }\end{array}$ & 0,670817 & $\begin{array}{l}\text { Mobile Social Network } \\
\text { App }\end{array}$ & 0,041982 \\
\hline $\begin{array}{l}\text { Mobile Social } \\
\text { Network App }\end{array}$ & 0,49506 & $\begin{array}{ll}\text { Project } & \text { Management } \\
\text { System } & \end{array}$ & 0,102811 \\
\hline $\begin{array}{l}\text { Content } \\
\text { Management } \\
\text { System }\end{array}$ & 0,483668 & Digital Library & 0,234673 \\
\hline Digital Library & 0,464703 & $\begin{array}{l}\text { Content Management } \\
\text { System }\end{array}$ & 0,716115 \\
\hline Enterprise portal & 0,413411 & Enterprise portal & 0,816793 \\
\hline $\begin{array}{l}\text { Corporate Web } \\
\text { Site }\end{array}$ & 0,375181 & Corporate Web Site & 0,853222 \\
\hline
\end{tabular}




\section{Gökçe Baysal Türkölmez}

Tablo 2 incelendiğinde, TOPSIS'e göre en iyi proje "Project Management System", ikinci en iyi proje "Mobile Social Network Application" olarak hesaplanmıştır. VIKOR, TOPSIS'e göre ikinci en iyi projeyi en iyi olarak seçmiştir. Seçilen en iyi projeler farklı olduğundan, üçüncü bir yöntem uygulayarak sonuçları karşılaşıımak nihai kararın verilmesi için önemlidir. Üçüncü yöntem olarak, çok kriterli yapı çok amaçlı optimizasyon problemine dönüştürülmüştür.

\section{Çok Amaçlı Optimizasyon Çözümü}

MatlabR2012a paket programı Optimizasyon Toolbox kullanılarak hesaplanan Genetik Algoritmalı Çok Amaçlı Optimizasyon Pareto yüzey grafikleri, amaç fonksiyonlarının ikili karşılaşıııımasına göre çizilmiştir.

Matlab çözümünde üretme için gelecek neslin çaprazlama oranı 0,8 olarak belirlenmiştir. Mutasyon için tekdüzen dağılış fonksiyonu seçilmiş ve mutasyon oranı 0,01 kullanılmıştır. Algoritmanın durma kriteri olarak 1000 iterasyon belirlenmiş, ancak 202 iterasyon sonrasında çözüm değerleri arasındaki fark minimum seviyeye indiği için, optimizasyon süreci tamamlanmıştır. Problemin çözümünde 202 iterasyon sonucunda toplam 73 Pareto optimal nokta bulunmuştur. Amaç fonksiyonlarının ikili karşılaştırmasını içeren Pareto-optimal yüz grafikleri Şekil 3'te verilmiştir. Beş amaç fonksiyonu olduğu için, tüm amaç fonksiyonlarını aynı grafikte göstermek mümkün olmamıştır.

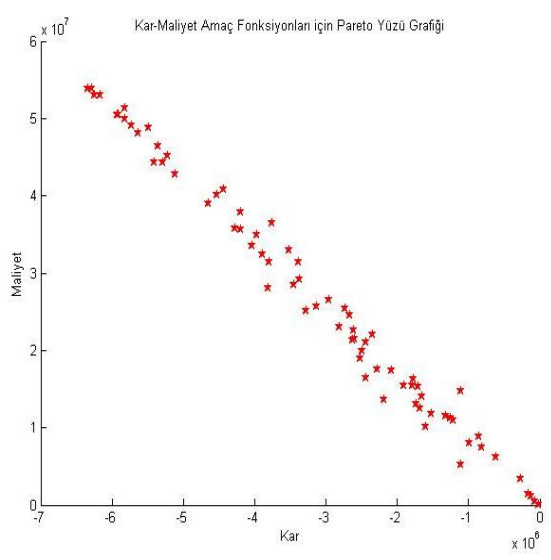

(a)

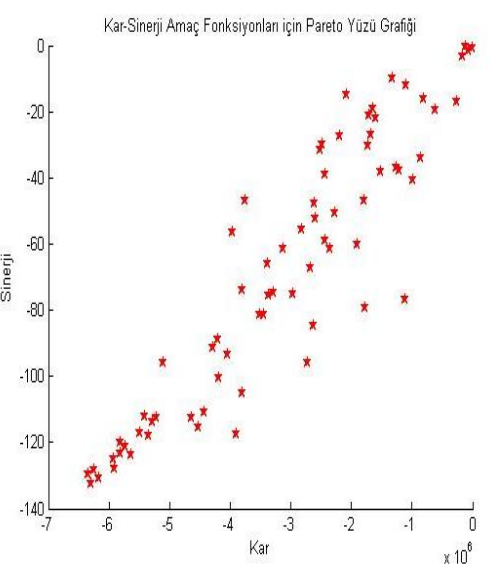

(b) 
Yazılım Projesi Seçim Probleminde

Çok Amaçlı Optimizasyon Uygulaması

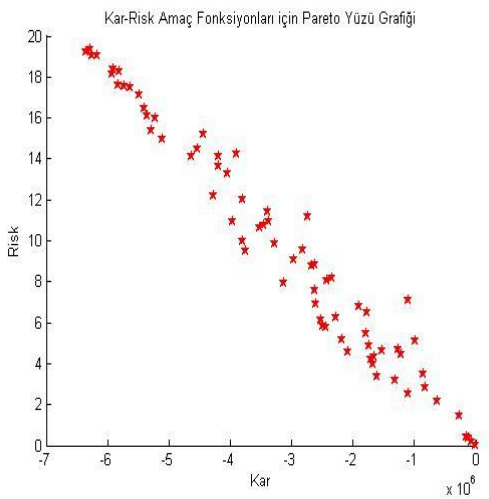

(c)

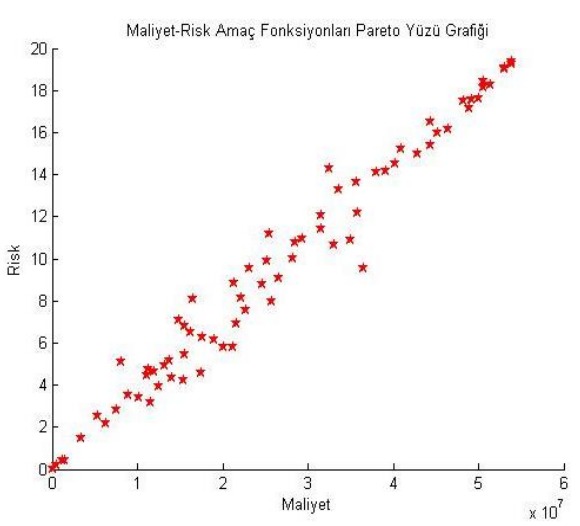

(e)

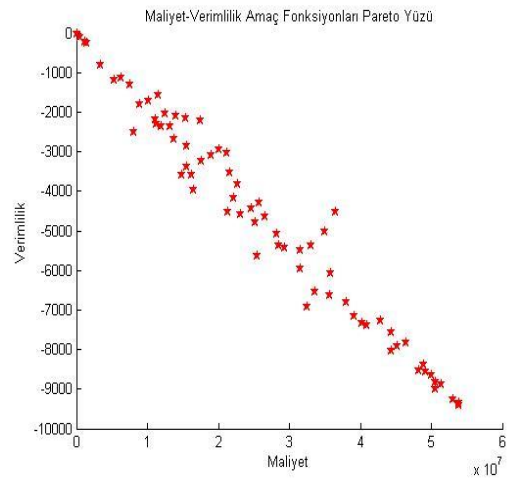

(g)

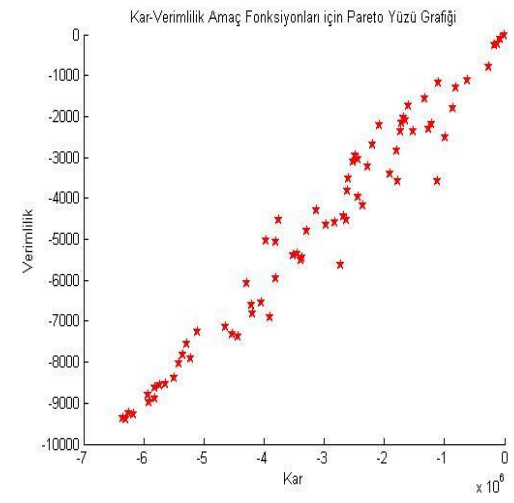

(d)

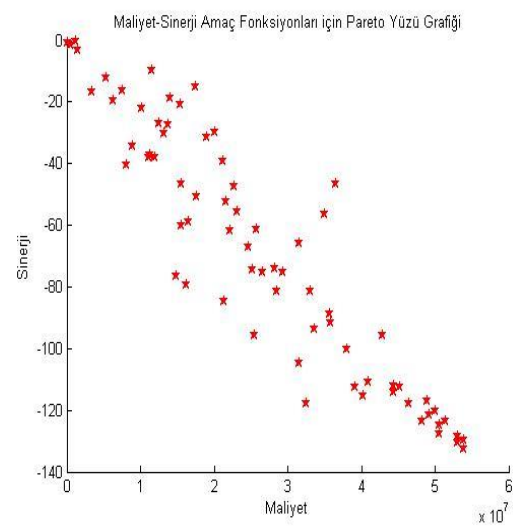

(f)

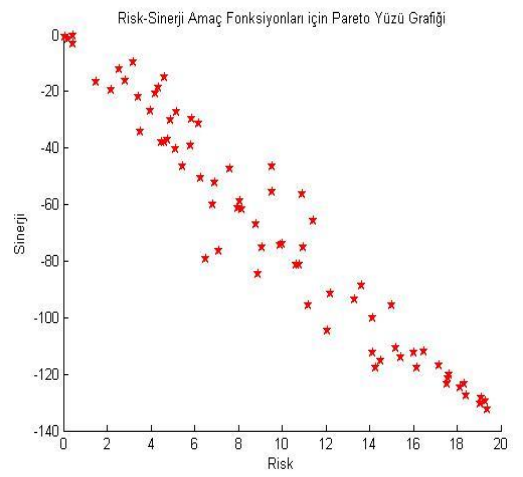

(h) 


\section{Gökçe Baysal Türkölmez}

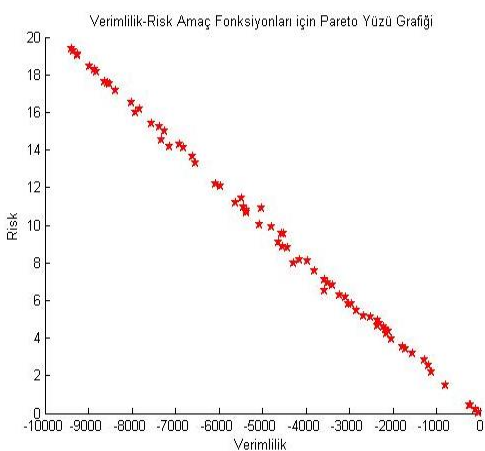

(1)

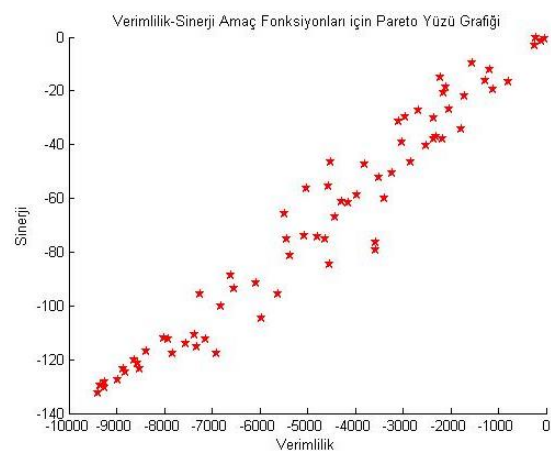

(i)

Şekil 3: Pareto-Optimal Yüz Grafikleri

(a) Kar-Maliyet, (b) Kar-Sinerji, (c) Kar-Risk, (d) Kar-Verimlilik, (e) Maliyet-Risk, (f) Maliyet-Sinerji, (g) Maliyet-Verimlilik, (h) Risk-Sinerji, (I) Verimlilik-Risk, (i) Verimlilik-Sinerji

Pareto-optimal yüz grafikleri aynı zamanda amaç fonksiyonları arasındaki ilişkiyi de göstermektedir. Şekil 3 incelendiğinde, kar-maliyet, kar-risk, maliyet-sinerji, maliyet-verimlilik, risk-sinerji ve verimlilik-risk arasında ters yönlü ilişki, kar-sinerji, kar-verimlilik, maliyet-risk ve verimlilik-sinerji arasında aynı yönlü ilişki olduğu görülmektedir.

Yazılım firması tüm kriterleri değerlendirerek en karlı projeye yatırım yapmak istemektedir. Pareto-optimal çözüm kümesini oluşturan 73 noktadan en yüksek kar değerini içeren 7 çözüm değeri, fonksiyonların ve değişkenlerin değerleri ile birlikte Tablo 3'te gösterilmektedir. İlk 7 çözümdeki kar değerleri çözüm kümesindeki diğer değerlerden oldukça fazladır. Tablodaki değerler yazııım firmasının yüksek kar hedeflerine uymaktadır.

\section{Tablo 3: Pareto-Optimal Küme İçinde En Karlı Yedi Çözüm Değeri}

\begin{tabular}{|c|c|c|c|c|c|c|c|c|c|c|c|}
\hline & kar & maliyet & verimlilik $\mathrm{r}$ & risk & sinerji & $\begin{array}{l}\text { enterpris } \\
\text { e portal }\end{array}$ & $\begin{array}{l}\text { project } \\
\text { managem } \\
\text { ent sys }\end{array}$ & $\begin{array}{l}\text { corpora } \\
\text { web sit }\end{array}$ & $\begin{array}{l}\text { digital } \\
\text { library } \\
\text { portal }\end{array}$ & $\begin{array}{l}\text { mobile } \\
\text { social } \\
\text { network }\end{array}$ & $\begin{array}{l}\text { content } \\
\text { managem } \\
\text { ent sys }\end{array}$ \\
\hline 31 & 47224.1 & 923578.3 & 3.68 & 19.2791 & 9.511 & 14.6594 & 22.4764 & .0007 & 20.7897 & 3.0111 & 0.0099 \\
\hline 45 & & 3.3 & & 6 & & & & & 54 & $.80 / 8$ & \\
\hline 7 & 51911.6 & 4 & 8.78 & & & & & & 20.3522 & 2.5736 & .359 \\
\hline 5 & 2536.6 & 530107 & 2.1 & 0423 & 523 & 14.5344 & 21.4764 & 81321 & 20.0397 & 2.8236 & 7.4224 \\
\hline 72 & 28704.1 & 005178 & 11.55 & 18.1562 & 124.765 & 14.0273 & 20.9912 & 8.72722 & 19.47 & 21.4235 & 5.978 \\
\hline 73 & 17928.3 & & 6.91 & 18.4319 & & 2887 & 21.2549 & 9.81171 & & 21.9119 & 7042 \\
\hline 66 & 5824741.8 & 938228.4 & 528.62 & 17.617 & 19.95 & 12.0718 & 20.2926 & 9.841 & 18.6313 & 22.0065 & 25.18 \\
\hline
\end{tabular}

Tablonun ilk sütunundaki rakamlar, Pareto-optimal kümedeki çözüm satırı sırasını göstermektedir. Kar, maliyet, verimlilik, risk ve sinerji amaç fonksiyonlarının çözüm değerleri ve fonksiyonların değişkenleri olan projelerin değerleri tabloda sırayla yer almaktadır. 


\section{Yazılım Projesi Seçim Probleminde \\ Çok Amaçlı Optimizasyon Uygulaması}

Tüm amaç fonksiyonları birlikte çözüldüğünde elde edilen maksimum toplam kar 6.347.224 Dolar olmaktadır. Fonksiyon değerlerini kar amaç fonksiyonunda yerine koyduğumuzda en yüksek karlı proje 2.301.112 Dolar ile "Mobile Social Network App" projesidir. Bu sonuç aynı zamanda VIKOR çözümündeki en iyi projedir. İkinci sırada en yüksek kar getiren proje 2.247.640 Dolar ile "Project Management System" projesidir. Bu sonuçlar TOPSIS ve VIKOR sonuçlarıyla da örtüşmektedir. Bu gelir seviyesinde işletme 53.923.578 Dolarlık toplam maliyetle karşılaşmaktadır. En maliyetli proje 21.676.313 Dolar ile aynı zamanda en yüksek karı getiren "Mobile Social Network App" projesidir.

\section{SONUÇLAR VE ÖNERİLER}

Proje seçim problemlerinde, yatırım kararını etkileyen birçok faktör vardır. Karar vericinin tüm faktörleri birlikte değerlendirerek seçim yapması gerekmektedir. Çok kriterli/amaçlı karar verme teknikleri, proje seçim problemlerinin çok faktörlü yapısına uygun çözüm algoritmalarına sahiptir. Bu çalışmada, bir yazııım firmasının altı projesi içinden yatırım yapacağı en karlı projenin seçilmesi amaçlanmıştır. Firma projelerini kar, maliyet, verimlilik, risk ve sinerji kriterlerine göre değerlendirmek istemektedir. Bu amaçla öncelikle çok kriterli karar verme yöntemlerinden TOPSIS ve VIKOR ile problem çözülmüştür. Sonuçta, TOPSIS'e göre en iyi proje VIKOR'da ikinci en iyi, VIKOR için en iyi proje de TOPSIS için ikinci en iyi proje olarak hesaplanmışıır. Verilecek nihai kararı desteklemek amacıyla, üçüncü bir yöntemle problem yeniden çözülmüştür. Bu aşamada problem, çok amaçlı optimizasyon yapısında formüle edilmiş ve evrimsel algoritmalarla çözülmüştür. "Mobile Social Network App" projesinin en yüksek kar getirisine sahip olduğu bulunmuştur. İkinci sırada "Project Management System" projesi yer almaktadır. Yazılım firmasının iki farkı çözüm yönteminde en karlı olarak seçtiği "Mobile Social Network App" projesine yatırım yapması önerilmektedir.

Bu çalışmada, çok kriterli karar verme yöntemleri ve çok amaçlı optimizasyon algoritmasının seçim problemlerinde kullanımı incelenmiştir. Farklı yapıdaki çözüm algoritmalarının, aynı ya da çok yakın sonuçlara ulaştığı görülmüştür. Özellikle, çok amaçlı optimizasyon, değişkenleri ve amaç fonksiyonlarının değerlerini de hesapladığı için diğer yöntemlere göre daha fazla bilgi sağlamaktadır. Çok Amaçlı Karar Verme yöntemleri projeler arasında en iyi olanların seçilmesine izin verecek bir sıralama sunmaktadır. Proje seçim problemlerinde bu yöntemlerin kullanımı, karar vericiye destek sağlaması açısından etkin sonuçlar vermektedir. 


\section{Gökçe Baysal Türkölmez}

Yazılım firması kriterler arasında bir derecelendirme yapmadığı için, kriterler/amaçlar eşit ağırlıklı alınmıştır. Ancak, amaçların eşit önemde olmadığı durumlarda ağırlık değerleriyle bu durum belirtilebilir. Sonraki çalışmalarda, kriterler/amaçlar ağırlıklandırılabilir. Böylece, ağırlıkların sonuca etkisi incelenebilir. Sadece sıralama değil, daha çok bilgiye ihtiyaç olduğu durumlarda Çok Amaçlı Optimizasyon uygun bir yöntem olarak önerilebilir.

\section{KAYNAKÇA}

Amiri, B. (2012). A multi-objective hybrid optimization algorithm for project selection problem. J Basic Appl Sci Res, 2(7), 6995-7002.

Chatterjee P, Athawale, V.M., Chakraborty S. (2010). Selection of industrial robots using compromise ranking and outranking methods. Robotics and Computer-Integrated Manufacturing, 26(5), 483-489.

De Weck, O. (2004). Multiobjective optimization: History and promise. Invited Keynote Paper, GL2-2, The Third China-Japan-Korea Joint Symposium on Optimization of Structural and Mechanical Systems, Kanazawa, Japan.

Deb, K. (2001). Multi-objective optimization using evolutionary algorithms (Vol. 16). Chichester, UK: John Wiley \& Sons.

Ghorbani, S. ve Rabbani, M. (2009). A new multi-objective algorithm for a project selection problem. Advances in Engineering Software, 40(1), 9-14.

Goldberg, D.E. (1989). Genetic algorithms in search, optimization and machine learning. Boston, MA: Addison-Wesley.

Hwang, C.L. ve Yoon, K. (1981). Multiple Attribute Decision Making. In: Lecture Notes in Economics and Mathematical Systems 186. Berlin: Springer-Verlag.

Kremmel, T., Kubalík, J., Biffl, S. (2010). Software project portfolio optimization with advanced multiobjective evolutionary algorithms. Applied Soft Computing, 11(1), 1416-1426.

Medaglia, A.L., Graves, S.B., Ringuest, J.L. (2007). A multiobjective evolutionary approach for linearly constrained project selection under uncertainty. European Journal of Operational Research, 179(3), 869-894.

Miettinen, K. (1999). Nonlinear multiobjective optimization (Vol. 12). Springer. 
Opricovic, S. ve Tzeng, G.H. (2004). Compromise solution by MCDM methods: A comparative analysis of VIKOR and TOPSIS. European Journal of Operational Research, 156, 445-455.

Rabbani, M., Bajestani, M.A., Khoshkhou, G.B. (2010). A multi-objective particle swarm optimization for project selection problem. Expert Systems with Applications, 37(1), 315-321.

Ringuest, J.L. ve Graves, S.B. (1989). The linear multi-objective R\&D project selection problem. IEEE Transactions on Engineering Management, 36(1), 54-57.

Sharma, T.N. (2011). Analysis of software cost estimation using COCOMO II. International Journal of Scientific \& Engineering Research, 2(6), 1-5.

Triantaphyllou, E. ve Lin, C.T. (1996). Development and evaluation of five fuzzy multiattribute decision-making methods. International Journal of Approximate Reasoning, 14(4), 281-310.

Tzeng, G.H., Lin, C.W., Opricovic, S. (2005). Multi-criteria analysis of alternative-fuel buses for public transportation. Energy Policy, 33, 1373-1383.

Zeleny, M. (1982). Multiple Criteria Decision Making. New York: McGrawHill. 